Instructions for authors, subscriptions and further details:

\title{
Finnish Lessons 2.0. What Can the World Learn from the Educational Change in Finland
}

José Taberner Guasp ${ }^{1}$

1) University of Córdoba, Spain

Date of publication: February 25th, 2017

Edition period: February 2017 - June 2017

To cite this article: Taberner Guasp, J. (2017). Finnish Lessons 2.0. What Can the World Learn from the Educational Change in Finland [Review of the Book]. International Journal of Sociology of Education, 6(1), 159-161. doi: 10.17583/rise.2017.2419

To link this article: http://dx.doi.org/10.17583/rise.2017.2419

\section{PLEASE SCROLL DOWN FOR ARTICLE}

The terms and conditions of use are related to the Open Journal System and to Creative Commons Attribution License (CC-BY) 


\section{Reviews}

Sahlberg, P. (2015). Finnish Lessons 2.0. What can the world learn from the educational change in Finland. Second edition. New York: Teachers College. Columbia University

- 7 ale la pena revisitar Finnish Lessons, tras haber leído en su momento la primera edición de 2011. No se limita a añadir al anterior prólogo de Andy Hargraves otro de Diane Ravitch, un prefacio propio y un epílogo de Ken Robinson. Importantes apartados cambian de título y/o sufren modificaciones parciales de contenido. Nos pone al día de cambios y nuevos retos educativos, aunque manteniendo toda la sustancia de la primera edición.

El profesor Sahlberg ha sido $-\mathrm{y}$ sigue siéndolo- testigo protagonista excepcional de la evolución del sistema educativo de su país. En cuanto a la formación del profesorado desde sus universidad o como director general de organismos relacionados con el Ministerio de Educación y Cultura. Un sistema escolar público universalizado (peruskoulu), conocido públicamente por la rigurosa selección y formación del profesorado -bien detallada en el libro-, por la equidad y buenos resultados. Todo ello es expuesto por Sahlberg en primera persona como un largo proceso de aplicación de políticas educativas y sociales combinadas, que consiguieron objetivar "el sueño finlandés".

Nos cuenta primero la evolución histórica nada fácil desde la doble red a la comprensividad. Revela luego principios pedagógicos de actuación en Finlandia que resultan paradójicos al ser comparados con la práctica dominante en la mayoría de países desarrollados tras sucesivas reformas.

Así "enseñar menos y aprender más" se traduce en menos horas lectivas, supresión de tareas externas para estudiantes pero más ayuda y orientación personalizada para aprender en la escuela, más horas de formación para docentes.

Uno de los puntos centrales de la exposición en ambas ediciones (cap. 4) -más enfatizado en la segunda - es su oposición frontal a lo que Sahlberg 
llama "GERM" (Global Educational Reform Movement). Un movimiento ayudado por poderosas Fundaciones y editoriales, liderado desde EE.UU, Inglaterra y otros países anglófonos. El GERM encarna la línea de política educativa dominante asociada al neoliberalismo: privatización, competencia segregadora e individualizada entre centros, profesorado, alumnado... profusión de exámenes, evaluaciones externas, rendición de cuentas del profesorado en base a resultados obtenidos por sus estudiantes y su centro...

Por el contrario, el modelo finlandés frente a la "competición entre escuelas" opone aprender unas de otras, cooperación de maestros y maestras entre sí, y también entre estudiantes... in situ y en redes institucionales o virtuales.

En vez del aprendizaje estandarizado proponen el personalizado. En vez de la priorización de Lengua, Matemáticas y Ciencias Naturales mirando al PISA adoptan un enfoque global de la educación en el que no se menosprecian Ciencias Sociales, Música o Arte. A la libre elección segregacionista- entre escuelas consiguen hacerla irrelevante al lograr equidad de resultados entre ellas y dentro de cada una de ellas.

Paradójicamente el sistema finlandés se ha servido de teorizaciones e innovaciones pedagógicas alumbradas en universidades norteamericanas y británicas, que allí no se aprovecharon: aprendizaje cooperativo, inteligencias múltiples, evaluaciones alternativas en el aula, peer coaching...

Los últimos resultados de PISA 2009-2012 y THALIS 2013, menos exitosos, han rebajado la autocomplacencia finlandesa. Ante los nuevos desafíos de la sociedad del conocimiento pretenden desarrollar actitudes y habilidades para usar la información e interacción disponible más allá del aula, para salir adelante en complejas redes sociales y virtuales, aprender a cooperar y resolver problemas creativos en grupos diversos... Con tal fin, la motivación, la creatividad, el descubrimiento del propio talento, la atención personalizada deben acrecentarse en el aula.

Se echa de menos en el libro información sobre la función de las familias en la escuela.

Desde la sociología pública y crítica también se pueden plantear interrogantes más allá del objetivo de este libro. Finlandia, desdichadamente, ocupa en Europa lugares de cabeza en violencia de género, alcoholismo y otras lacras. Aquellas cohortes escolares que asombraron al mundo en el primer PISA no son ajenas a esas tasas actuales. Con toda la cautela contextuada que merece tan compleja cuestión, cabría preguntarse si desde 
RISE - International Journal of Sociology of Education, 4(2) 161

el sistema educativo se podría ayudar a mejorar el bienestar social en esos campos.

José Taberner Guasp, Universidad de Córdoba pptaberner@gmail.com 